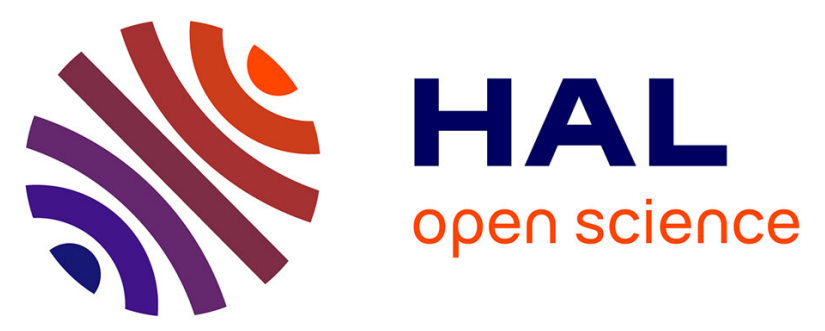

\title{
Antagonistic effect of natural habitat conversion on community adjustment to climate warming in nonbreeding waterbirds
}

Elie Gaget, Thomas Galewski, Frédéric Jiguet, Anis Guelmami, Christian Perennou, Coralie Beltrame, Isabelle Le Viol

\section{To cite this version:}

Elie Gaget, Thomas Galewski, Frédéric Jiguet, Anis Guelmami, Christian Perennou, et al.. Antagonistic effect of natural habitat conversion on community adjustment to climate warming in nonbreeding waterbirds. Conservation Biology, 2019, 10.1111/cobi.13453 . hal-02515759

\section{HAL Id: hal-02515759 \\ https://hal.science/hal-02515759}

Submitted on 23 Mar 2020

HAL is a multi-disciplinary open access archive for the deposit and dissemination of scientific research documents, whether they are published or not. The documents may come from teaching and research institutions in France or abroad, or from public or private research centers.
L'archive ouverte pluridisciplinaire HAL, est destinée au dépôt et à la diffusion de documents scientifiques de niveau recherche, publiés ou non, émanant des établissements d'enseignement et de recherche français ou étrangers, des laboratoires publics ou privés. 


\section{Antagonistic effect of natural habitat conversion on community}

\section{adjustment to climate warming in nonbreeding waterbirds}

Elie Gaget ${ }^{1,2}$, Thomas Galewski ${ }^{1}$, Frédéric Jiguet ${ }^{2}$, Anis Guelmami ${ }^{1}$, Christian Perennou ${ }^{1}$, Coralie Beltrame ${ }^{1}$ and Isabelle Le Viol ${ }^{2}$

${ }^{1}$ Institut de recherche pour la conservation des zones humides méditerranéennes, Tour du Valat, le Sambuc, 13200 Arles, France

${ }^{2}$ Muséum National d'Histoire Naturelle, Centre d"Ecologie et des Sciences de la Conservation-CESCO - UMR 7204 MNHNCNRS-Sorbonne Universités, Station de biologie marine, 29900 Concarneau/43 rue Buffon, 75005 Paris, France Author for correspondence: Elie Gaget, Tour du Valat, Le Sambuc, 13200 Arles, France. E-mail: elie.gaget@gmail.com

How to cite : Gaget E., Galewski T., Jiguet F., Guelmami A., Perennou C., Beltrame C., Viol I.L. Antagonistic effect of natural habitat conversion on community adjustment to climate warming in nonbreeding waterbirds. Conservation Biology. doi: $\underline{10.1111 / \text { cobi.13453 }}$

Keywords: Community temperature index, interaction, land use change, Mediterranean, niche position, niche breadth, wetlands

Article impact statement: Waterbird communities do not adjustment to climate warming when natural habitat conversion is $>5 \%$ over 15 years.

\section{Abstract}

While the impacts of climate and land use changes on biodiversity have been widely documented, their joint effects remain poorly understood. We evaluated how non-breeding waterbird communities adjust to climate warming along a gradient of land use change. Using mid-winter waterbird counts (132 species) at 164 major non-breeding sites in 22 Mediterranean countries, we assessed the changes in species composition during 1991-2010, regarding thermal niche position and breadth, in response to regional and local winter temperature anomalies and to natural habitat conversion. We showed that in response to the temperature increase, communities became relatively richer in warm-dwelling species, but less where natural habitat conversion occurred. At the sites affected by natural habitat conversion, the overall species richness decreased with time, while the abundance relatively increased for the species with a broader thermal niche, independently of their thermal affinities. The strong negative relationship between natural habitat conversion and community adjustment to temperature increases suggests an antagonistic interaction between climate warming and habitat change. Indeed, we found no evidence of community adjustment to climate warming when natural habitat conversion was higher than $5 \%$ over 15 years. These results underline the importance of habitat conservation in community adjustment to climate warming.

\section{Introduction}

Climate warming and land use change are among the strongest drivers of biodiversity changes, and their combination has major consequences for its conservation (Pereira et al. 2010). A temperature increase is likely to increase the relative abundance of warm-dwelling species (Devictor et al. 2008), while land use change decreases the relative abundance of habitat-specialized species (Clavel et al. 2011). An increasing body of literature reports interacting effects between climate warming and land use change on species abundance as being either synergistic or antagonistic (Brook et al. 2008; Oliver and Morecraft 2014; and Côté et al. 2016). A synergetic interaction between climate warming and land use changes should result in an increase in warm-dwelling and habitat generalist species, while an antagonistic one could result in the apparent lack of species response to one driver. As an example, climate warming and the conversion of tropical forest to farmland lead to an increase in abundance of warm-dwelling birds, adapted to warmer and drier conditions (synergic, Frishkoff et al. 2016), while major land use changes in Europe likely prevent the increase of warm-dwelling bird despite climate warming (antagonistic, Kerbiriou et al. 2009; Galewski and Devictor 2016). Yet, the 
detection of the interaction effect depends on the magnitude of the biological changes, which is influenced by the intensity of the driver (Côté et al. 2016). To date, few empirical studies have explored species thermal tolerance (Jiguet et al. 2006) in relation to a gradient of land use change interacting with climate warming (Oliver and Morecraft 2014; Pearce-Higgins and Green 2014; Sirami et al. 2016).

Species tolerance and persistence facing one or more drivers of change are related to the breadth of their ecological niche (Hutchinson 1957) and to the position where these changes occur within the niche along suitable environmental gradients (Grenouillet and Comte 2014). Generalist species, with larger niche dimensions, have a higher tolerance to environmental variations (Clavel et al. 2011) or extreme events (Jiguet et al. 2006). Conversely, specialists have smaller niche dimensions, but they show a higher performance in exploiting their environmental niche when conditions are favourable (Poisot et al. 2011). Since niche breadth is correlated between the different dimensions of the niche (Brown 1984), i.e. specialist species are usually specialists in more than one niche dimension (Barnagaud et al. 2012; Carboni et al. 2016), specialist species are presumed to be more vulnerable to the joint effects of several drivers of biodiversity changes (Slatyer et al. 2013). In case of interaction between climate warming and land use change, one would then expect land use change would reduce the abundance of specialist species more than that of generalist species (Clavel et al. 2011), which are probably both thermal and habitat generalists due to the correlations between niche dimensions (Barnagaud et al. 2012).

To assess these responses, the community weighted mean trait indices (Lavorel et al. 2008) are useful approaches based on species niche position and breadth, commonly used to investigate community adjustment to climate warming and land use change (Devictor et al. 2008; Clavel et al. 2011). Due to climate warming, the average thermal affinity of the community (hereafter, community temperature index, CTI) assessed with the species thermal niche positions (hereafter, species temperature index STI) is expected to increase (Devictor et al. 2008). Similarly, due to additional land use change (Clavel et al. 2011) or high temperature variation (Jiguet et al. 2006) the average thermal range of community (hereafter, community temperature range, CTR) assessed with the species thermal niche range (hereafter, species temperature range STR) is expected to increase. While the CTI increase with temperature is largely described, notably for breeding (e.g. Devictor et al. 2008; Gaüzère et al. 2016) and non-breeding birds (Godet et al. 2011; Gaget et al. 2018), the CTR should provide additional insights on why alternative CTI changes can be observed in case of significant land use change (e.g. Kerbiriou et al. 2009; Galewski and Devictor 2016).

Here, we investigated changes in the thermal niche position and breadth of non-breeding waterbird communities according to changes in temperature and to natural habitat conversion (NHC). We considered the changes in species abundance $(n=132)$ at 164 sites across the Mediterranean basin ( $n=22$ countries) during 20 years. We described community changes in terms of species thermal affinity by using the $\mathrm{CTI}$ and species thermal range by using the CTR. By determining species contributions to changes in these two community indices (Princé and Zuckerberg 2015), we evaluated which species relatively increased in abundance with increasing temperature or with the interaction between increasing temperature and NHC. We thus hypothesized that 1 ) the relative abundance of the warm-dwelling species will increase (CTI increase) with increasing temperature, and 2) the relative abundance of thermal generalists will increase (CTR increase) with the interaction between NHC and increasing temperature.

\section{Material and methods}

\section{Study sites: temperature changes and NHC}

We focused on the Mediterranean region (22 countries, Fig. 1). This region faces rapid land conversion (Newbold et al. 2015) and climate warming $\left(+0.25^{\circ} \mathrm{C}\right.$ per decade in winter, Mariotti et al. 2015, Appendix S1). Using the HadCRUT4 dataset (Morice et al. 2012), we calculated local (Tanom 
Local, $0.5^{\circ}$ grid resolution and based on the geographic coordinates of the monitored site) and regional (Tanom Regional, Mediterranean region, $30^{\circ} \mathrm{N}-45^{\circ} \mathrm{N}$ and $10^{\circ} \mathrm{W}-40^{\circ} \mathrm{E}$ ) winter temperature anomalies as the average of the mean temperature of November, December and January per year minus the average temperature of these months over the 1991-2010 period (Pearson correlation: rTanom Local-Tanom Regional $=0.45$, rTanom Regional-Year $=0.32$, and rTanom Local-Year $=0.37$ ).

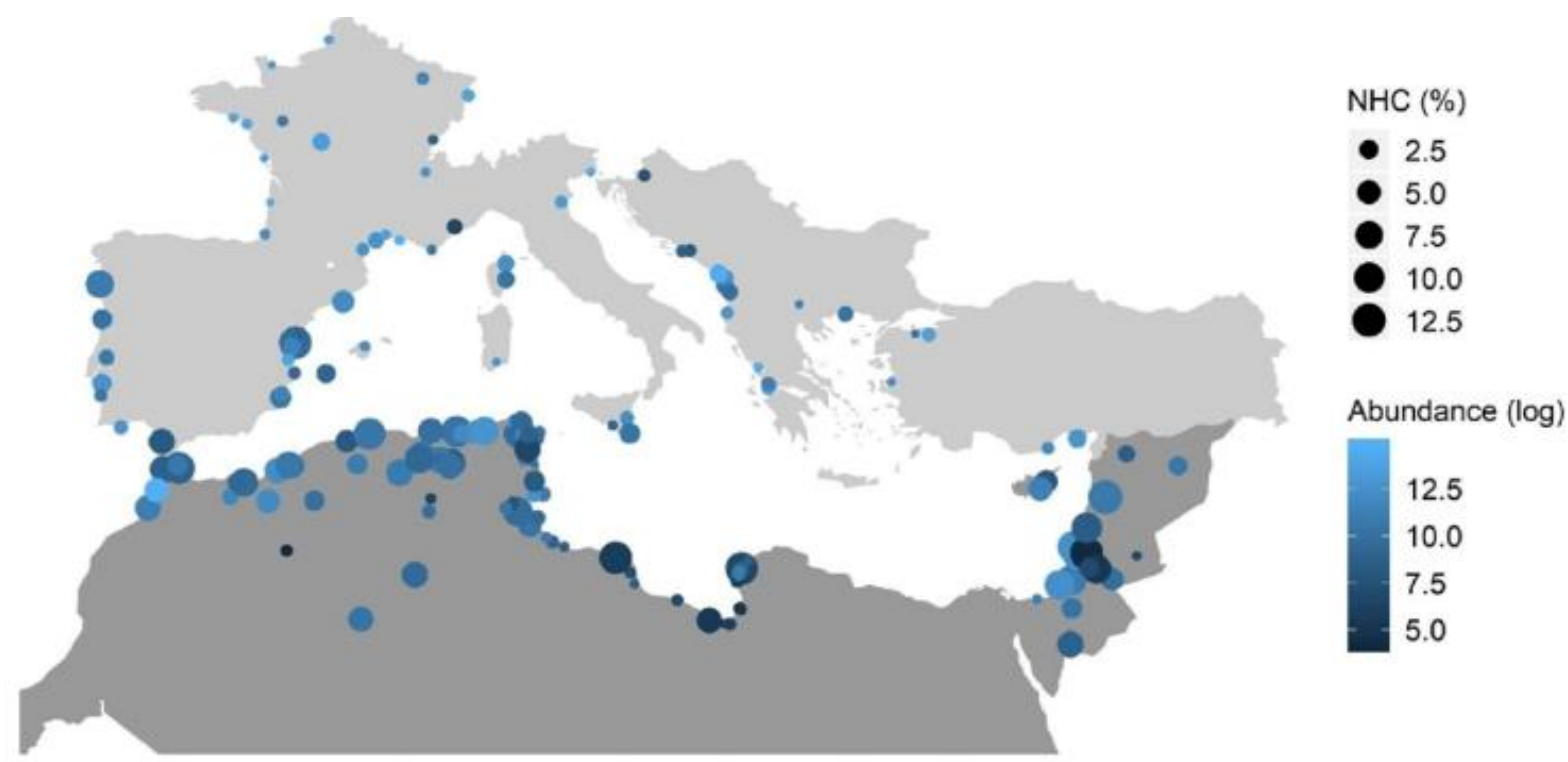

Figure 1:Distribution of the monitored sites in the Mediterranean Basin ( $n=164)$. Point size is proportional to the natural habitat conversion (NHC) and point colour corresponds to the non-breeding waterbird average abundance (log), light blue for the more numerous. Light and dark grey colours correspond to the northern and the southern shore, respectively

To document the NHC at 164 bird-surveyed sites, we used the GlobWetland-II database (http://www.globwetland.org). Land cover data in 1990 and 2005 were derived from Landsat satellite images (see Beltrame et al. (2015); Perennou et al. (2018) for methods, resolution of 30m). From the classification provided by Perennou et al. (2018) we defined as "natural habitats", habitats with reduced anthropogenic impacts (e.g., marshes, rivers, lagoons, reedbeds, or grasslands) and "man-made habitats" as habitats intensively impacted by anthropogenic activities (e.g., urban area, agricultural lands, dams, salines or reservoirs). We measured the proportion of NHC at each site between 1990 and 2005 (reported error rate across natural and man-made habitats: 4.42\%).

\section{Waterbird monitoring}

Waterbirds were monitored under the framework of the International Waterbird Census programme (see Delany (2005) for the protocol). A single annual count in January was performed to monitor the waterbird populations during the non-breeding season, by both professional and volunteering ornithologists under the coordination of Wetlands International (www.wetlands.org). Bird species abundance data were used for the 164 sites covered by the GlobWetland-II database. In order to study the long-term changes in community composition, these sites met the following criteria: (1) at least two counts between 1991 and 2010 and (2) more than five wetland species recorded during each count. We considered the 132 species of the Western Palearctic region that were listed in the African-Eurasian Migratory Waterbird Agreement (AEWA, http://www.unep-aewa.org; Appendix S2), corresponding to species for which the Mediterranean Basin is an important region during the nonbreeding season ( $97 \%$ of full migratory species). The dataset included 1,797 count events and 36.8 million counted birds, with on average 11.0 (SD 5.2) count events per site across the two decades, and 90 (SD 17) surveyed sites per year, without temporal trend during the study period (linear model, $p>0.5$ ). 


\section{Species temperature metrics and species trait originalities}

To calculate the CTI and CTR, we first determined the winter STI and the winter STR. The winter STI was assessed following Gaget et al. (2018) adapted from the breeding STI (Devictor et al. 2008), as the average of the mean temperature of January (WorldClim database, http://worldclim.org/, resolution 0.05 decimal degree, from 1950-2000) across the non-breeding species range in the African-Eurasian region covered by the AEWA (extracted from www.birdlife.org 2015). The STR was assessed as the interval between the average temperatures of the thermal minimum ( $5 \%$ lower) and maximum (95\% upper) of the non-breeding species thermal range (see Gregory et al. (2009)). STI and STR refer to the thermal niche position and the thermal niche breadth of the species, respectively, and were not correlated ( $r$ Pearson $=-0.11, p=0.2$ ).

To determine whether species were cold- vs. warm-dwelling and thermal specialists vs. generalists, we computed „species trait originalities". The species trait originality is a measure of the extent to which the species temperature metric value differs from those of the other species in the community. We computed the species trait originality as the difference between the species temperature metric value and the average community weighted mean of the presence/absence data in the study area (Mediterranean Basin). Cold-dwelling (or, conversely, warm-dwelling) species have an STI below (above) the average CTI, and thermal specialist (or, conversely, generalist) species have an STR below (above) the average CTR.

\section{Data analysis}

\section{Community weighted mean indices}

We computed the CTI and CTR to evaluate changes in the thermal average and thermal range composition in communities. The CTI was calculated by weighting the STI value of each species inside a community by the $\log (x+1)$ of its abundance divided by the log of total species abundance, following Godet et al. (2011). We calculated similarly the CTR, using the STR instead of the STI (Appendix S3).

We evaluated how the CTI and CTR varied with NHC, with the proxies of climate warming (Tanom Local, Tanom Regional and year as a global warming proxy) and their interaction. We performed three different generalized linear mixed models (GLMMs, Gaussian error distributions, package nlme, Pinheiro et al. 2014) using one of the climate proxies per model. The response variable was the CTI or the CTR. The explanatory terms were the fixed effects and interactions between NHC and the climate proxy. The sites nested within a country were used as random effects to deal with the heterogeneity in national monitoring schemes (Gaget et al. 2018). The variables were standardized per site to focus on inter-annual variations. We added an exponential structure based on the geographical coordinates and verified the absence of spatial autocorrelation in the model residuals via autocorrelation plot checking (Zuur et al. 2009).

We performed complementary analyses to investigate potential bias. First, we verified that the site size, used as a covariable did not affect the results. Second, as the NHC was lower in the north of the Mediterranean Basin (Appendix S4, Fig. 1), we checked whether the CTI and CTR trends differed among the northern and southern Mediterranean shores. We used the same methodology as previously described (with the year, NHC and their interaction as fixed effects) and ran two individual GLMMs of the northern (Portugal to Turkey, $n=61$ sites) and southern (Morocco to Syria, $n=103$ sites) shores of the Mediterranean region. Third, we assessed whether the CTI and CTR trends were driven by a few abundant species by calculating them from the presence/absence data only. Species contributions.

We assessed species-specific contributions to the CTI and CTR trends. We used a jack-knife approach, in which species were removed one by one from the dataset to compute CTI and CTR values without the effect of the removed species (Princé and Zuckerberg 2015). The difference between the CTI (or 
CTR) trend based on all species and the CTI (or CTR) trend based on all species minus species $\mathrm{i}$ corresponded to the contribution of species i. A species resulting in a CTI increase (or, conversely, decrease) with time had a positive (or, conversely, negative) contribution; the same applies for the CTR (Gaget et al. 2018).

\section{Relative species trend}

We inferred the relative species abundance trend from the species contributions to the CTI and CTR trends. Species contribution depended on the relative species trait originality and relative species population trend (Gaget et al. 2018). A species was relatively decreasing when 1 ) it had either a positive contribution and a positive trait originality or 2) a negative contribution and a negative trait originality. Conversely, a species was relatively increasing when 1 ) it had either a negative contribution and a positive trait originality or 2) a positive contribution and a negative trait originality. We mapped the distribution of the species that relatively increased and decreased (CTI contribution $>1 \%$ ) using species distribution maps extracted from www.birdlife.org (2015), which were weighted by the species contribution to the CTI trend.

\section{Trends in overall abundance and species richness}

We estimated the temporal trends in abundance and species richness using GLMMs, with negative binomial distribution for the abundance, and Poisson error distribution for the species richness (package glmmTMB, Magnusson et al. 2017). We used the fixed effects and interactions between $\mathrm{NHC}$ and year and the random effect of the sites nested within the corresponding country. We controlled for spatial autocorrelation as in previous models.

Statistical analyses were performed with R 3.3.0 (R 2015), and the model residuals were graphically inspected to verify the model validity (Zuur et al. 2009). Graphical representations of the CTI and CTR interaction trends were generated with the visreg R package (Breheny et al. 2013) by combining 2D surface plots and segmented plots for $0 \%, 5 \%$, and $10 \%$ NHC.

\section{Results}

\section{Natural habitat conversion}

For these study sites, the natural habitats covered in average 65\% (SD 27) of the site surface in 2005, which represented a decrease of 0-13\% since 1990 (on average 2.95 (3.40 SD), Appendix S4, S5). Approximately $60 \%$ of the $\mathrm{NHC}$ was due to conversion to man-made wetlands, $\mathrm{A} 0 \%$ to agriculture and $10 \%$ to urbanisation. 
CTI and CTR changes

The CTI increased during the twenty years of monitoring $(p<0.001$, Table 1$)$.

\begin{tabular}{|c|c|c|c|c|c|c|c|}
\hline & Variables & Estimate & SE & DF & $t$ & $p$ & $\mathrm{R}^{2}$ \\
\hline \multirow{9}{*}{ CTI } & $\mathrm{NHC}$ & 0.00 & 0.02 & 162 & 0.06 & 0.953 & \multirow{3}{*}{$\begin{array}{l}\mathrm{R}_{\mathrm{m}}^{2}=0.025 \\
\mathrm{R}_{\mathrm{c}}^{2}=0.740\end{array}$} \\
\hline & Year & 0.18 & 0.02 & 1631 & 8.17 & $<0.001$ & \\
\hline & NHC:Year & -0.09 & 0.02 & 1631 & -4.06 & $<0.001$ & \\
\hline & $\mathrm{NHC}$ & 0.04 & 0.03 & 162 & 1.43 & 0.155 & \multirow{3}{*}{$\begin{array}{l}R_{m}^{2}=0.011 \\
R_{c}^{2}=0.739\end{array}$} \\
\hline & Tanom Regional & 0.13 & 0.05 & 1631 & 2.69 & 0.007 & \\
\hline & NHC:Tanom Regional & -0.16 & 0.05 & 1631 & -3.25 & 0.001 & \\
\hline & $\mathrm{NHC}$ & 0.00 & 0.02 & 162 & -0.10 & 0.923 & \multirow{3}{*}{$\begin{array}{l}R_{m}{ }^{2}=0.010 \\
R_{c}{ }^{2}=0.737\end{array}$} \\
\hline & Tanom Local & 0.01 & 0.02 & 1631 & 0.78 & 0.433 & \\
\hline & NHC:Tanom Local & -0.04 & 0.02 & 1631 & -2.30 & 0.020 & \\
\hline \multirow{9}{*}{ CTR } & $\mathrm{NHC}$ & 0.00 & 0.12 & 162 & 0.03 & 0.974 & \multirow{3}{*}{$\begin{array}{l}\mathrm{R}_{\mathrm{m}}{ }^{2}=0.021 \\
\mathrm{R}_{\mathrm{c}}{ }^{2}=0.631\end{array}$} \\
\hline & Year & -0.26 & 0.03 & 1631 & -8.45 & $<0.001$ & \\
\hline & NHC:Year & 0.12 & 0.03 & 1631 & 3.69 & $<0.001$ & \\
\hline & $\mathrm{NHC}$ & 0.00 & 0.13 & 162 & 0.01 & 0.996 & \multirow{3}{*}{$\begin{array}{l}R_{m}{ }^{2}=0.002 \\
R_{c}^{2}=0.624\end{array}$} \\
\hline & Tanom Regional & -0.18 & 0.07 & 1631 & -2.80 & 0.005 & \\
\hline & NHC:Tanom Regional & 0.11 & 0.07 & 1631 & 1.63 & 0.104 & \\
\hline & $\mathrm{NHC}$ & 0.03 & 0.12 & 162 & 0.20 & 0.844 & \multirow{3}{*}{$\begin{array}{l}\mathrm{R}_{\mathrm{m}}^{2}=0.010 \\
\mathrm{R}_{\mathrm{c}}{ }^{2}=0.620\end{array}$} \\
\hline & Tanom Local & -0.02 & 0.02 & 1631 & -0.88 & 0.380 & \\
\hline & NHC:Tanom Local & 0.01 & 0.02 & 1631 & 0.40 & 0.692 & \\
\hline \multirow{3}{*}{ Ab. } & $\mathrm{NHC}$ & -0.40 & 0.14 & 162 & -2.88 & 0.004 & \multirow{3}{*}{$\begin{array}{l}R_{m}^{2}=0.040 \\
R_{c}^{2}=0.887\end{array}$} \\
\hline & Year & 0.01 & 0.02 & 1631 & 0.47 & 0.636 & \\
\hline & NHC:Year & 0.02 & 0.02 & 1631 & 0.95 & 0.341 & \\
\hline \multirow{3}{*}{ S.R. } & $\mathrm{NHC}$ & -0.14 & 0.04 & 162 & -3.34 & 0.001 & \multirow{3}{*}{$\begin{array}{l}\mathrm{R}_{\mathrm{m}}{ }^{2}=0.046 \\
\mathrm{R}_{\mathrm{c}}{ }^{2}=0.879\end{array}$} \\
\hline & Year & 0.10 & 0.01 & 1631 & 17.99 & $<0.001$ & \\
\hline & NHC:Year & -0.03 & 0.01 & 1631 & -5.24 & $<0.001$ & \\
\hline
\end{tabular}

Tableau 1: Effects of natural habitat conversion (NHC) on the community temperature index (CTI) and community temperature range (CTR) using three proxies of climate warming: the year, Tanom Regional for regional temperature anomalies and Tanom Local for local tem. ${ }_{a}$ Both $R_{m 2}$ (marginal and fixed effect only) and $R_{c 2}$ (conditional and full model) values were reported (Nakagawa and Schielzeth, 2013).

The CTI also increased, more moderately, with $\mathrm{T}_{\text {anom Regional }}$ but not with $\mathrm{T}_{\text {anom Local }}$ (Table 1, Fig. 2a). However, the interaction was negative between NHC and years $\left(P=-0.09, p<0.001\right.$, Fig. 2a), $T_{\text {anom }}$ Regional $(P=-0.16, p=0.001)$ or $T_{\text {anom Local }}(P=-0.04, p=0.02)$ (Table 1$)$. In other words, the higher the habitat conversion was, the lower the CTI increase during the study period or the lower the CTI increase as a function of $\mathrm{T}_{\text {anom }}$ Regional or $\mathrm{T}_{\text {anom Local. }}$. Note that the apparent $\mathrm{CTI}$ decrease as a function of $\mathrm{T}_{\text {anom Regional }}$ and $\mathrm{T}_{\text {anom Local }}$ when $\mathrm{NHC}>10 \%$ was not significant (Appendix S7). On both sides of the Mediterranean, we found a similar CTI increase $\left(P_{\text {Northern }}=0.25, p<0.001 ; P_{\text {Southern }}=0.27, p<0.001\right)$ and a similar negative interaction $\left(P_{\text {Northern }}=-0.16, p<0.01 ; P_{\text {Southern }}=-0.13, p<0.02\right)$. 
(a) CTI

(1) Year

(2) Regional temperature anomalies

(3) Local temperature anomalies

(b) CTR

(1) Year

(2) Regional temperature anomalies

(3) Local temperature anomalies
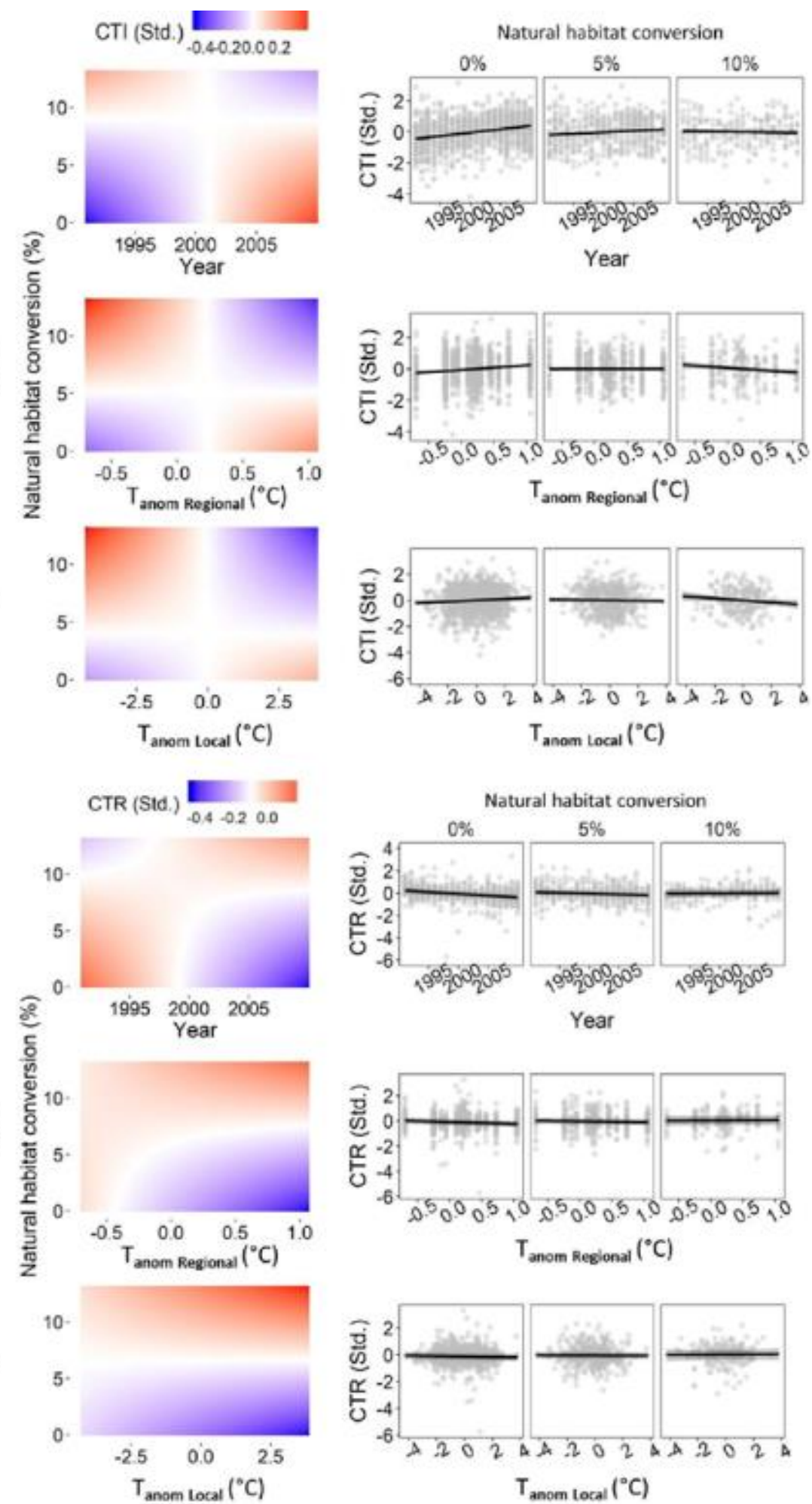

Figure 2: Community temperature index (CTI, standardized) (a) and community temperature range (CTR, standardized) (b) over three proxies of climate warming: (1) year, (2) regional ( $\left.T_{\text {anom Regional }}\right)$ and (3) local temperature anomalies ( $\left.T_{\text {anom Local }}\right)$, and over natural habitat conversion (\%) by 2D surface plots with colour gradients depending on the CTI or CTR

The CTR decreased with time $(P=-0.14, p<0.001$, Table 1, Fig. $2 b)$ but decreased less with time when the NHC increased $(P=0.06, p<0.001$, Fig. 1, Table 1, Fig. $2 b) . T_{\text {anom Regional }}$ had a significant negative effect on CTR ( $P=-0.10, p=0.005)$ but not $T_{\text {anom Local }}$ (Table 1 , Fig.

2b). Similar trends were found for CTI and CTR based on species abundance (Table 1 ) and species 
presence/absence (Appendix S6; one exception was a change in significance for the CTR trend as a function of $T_{\text {anom Regional }}$ ), suggesting that the trends were not driven solely by the most abundant species.

\section{Species contributions}

Twenty-four species among the $132(18 \%)$ were highly contributing to the CTI trend, with a contribution higher than 1\% (Fig. 3, Appendix S2). Among these 24 species, 71\% were relatively increasing, and $82 \%$ were warm-dwelling specialists (STR originality $<0$ and STI originality $>0$ ), mainly spending the non-breeding season on the southern Mediterranean shore (Fig. 4). Conversely, seven cold-dwelling species, i.e., species with a northern distribution (Fig. 4), were relatively decreasing (contribution higher than $1 \%$ ).
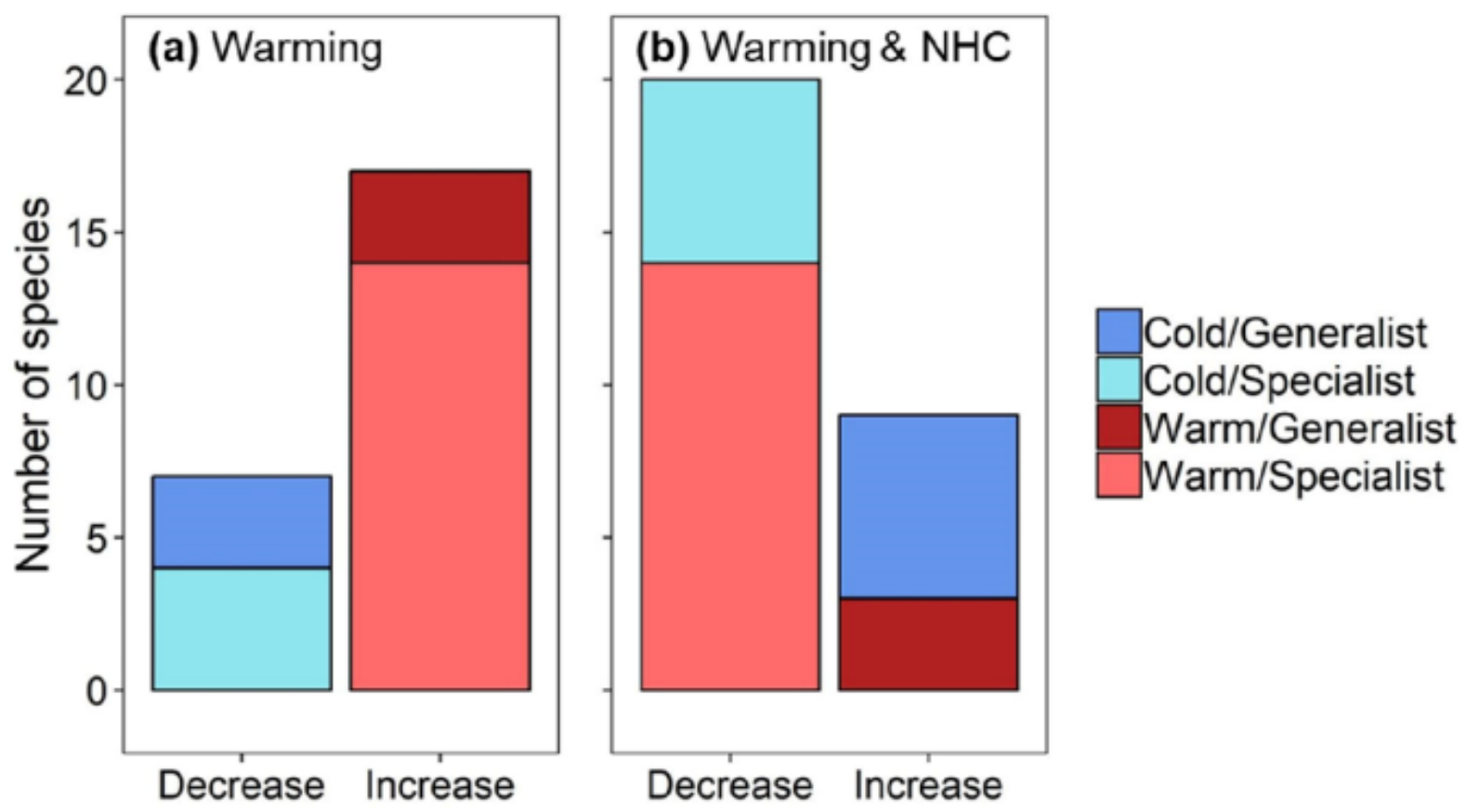

Relative species abundance trend

Figure 3 : Number of species with relative increasing or decreasing abundances, according to their contributions to CTI values over the years (a) and to CTR values over the years, considering the interactions with natural habitat conversion (NHC) (b). The species trends of cold-vs. warm-dwelling species and thermal specialist vs. generalist species (1991-2010) are relative to the overall species trends. 


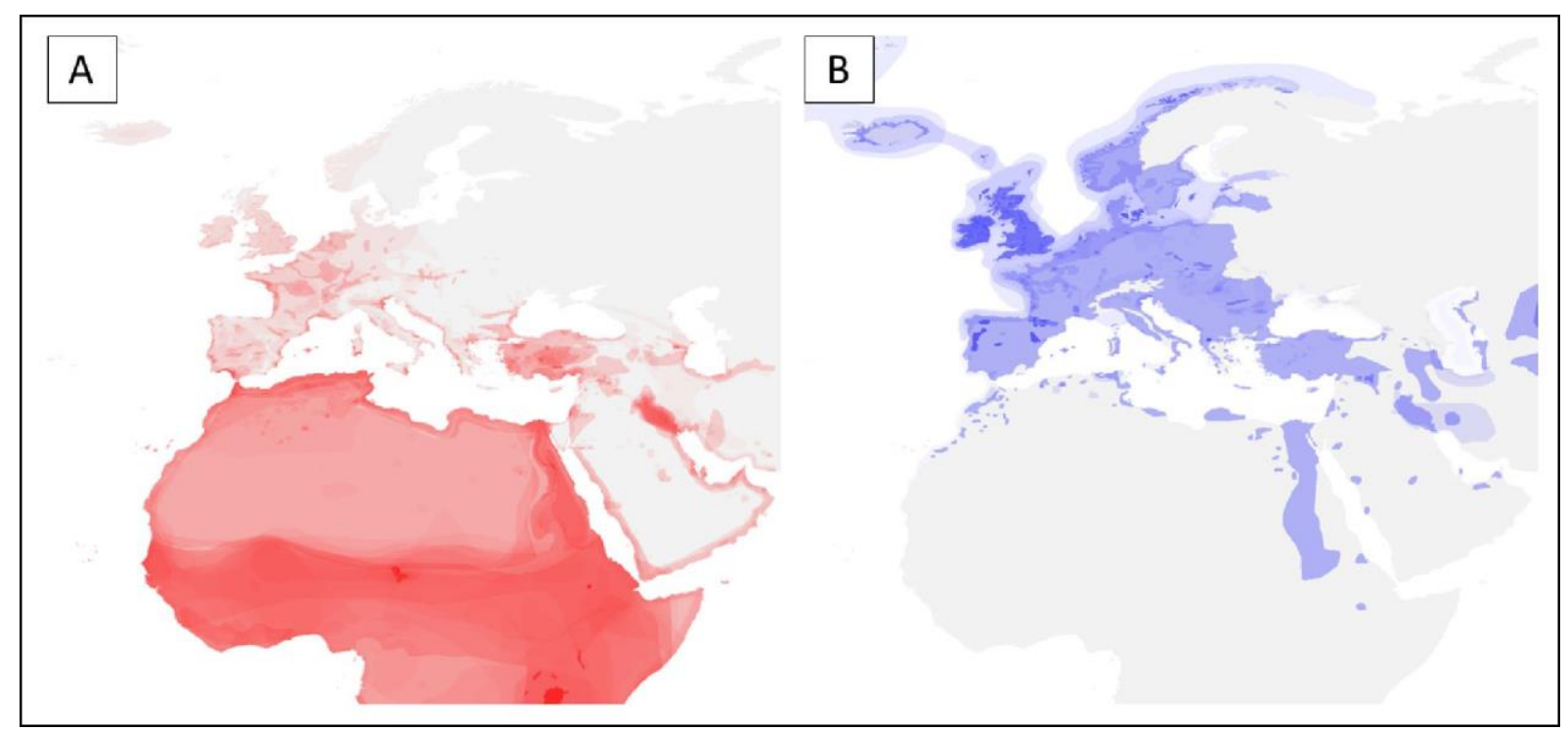

Figure 4: Non-breeding distribution of the species relatively increasing $(A, n=17)$ and decreasing $(B, n=7)$ in abundance over the years (CTI contribution $>1 \%$ ). The light to dark colour contrast corresponds to the superposition of species distributions (distribution maps extracted from www.birdlife.org 2015) weighted by the species contributions to the CTI trend (Appendix S1).

Twenty-nine species (30\%) contributed positively and more than $1 \%$ to the interaction effect between the years and NHC on CTR (Fig. 3, Appendix S2). Among these species, $69 \%$ were relatively declining, of which $70 \%$ were warm-dwelling specialists. The species that were relatively increasing with NHC over time were all thermal generalists (STR originality $>0$ ), either cold- or warm-dwelling (Fig. 3).

Over time, the overall abundance displayed a non-significant trend $(\beta=0.01, p=0.6)$, but species richness increased $(\beta=0.10, p<0.001)$ (Table 1$)$. The abundance and species richness were lower at sites where the NHC was higher $(\beta=-0.40, p<0.001 ; \beta=-0.14, p<0.001$, Table 1$)$. The species richness decreased with the interaction between time and NHC

$(\beta=-0.03, p<0.001)$, but the interaction had no significant effect on abundance $(\beta=0 A 02, p=0.3)$.

\section{Discussion}

Our results suggest that non-breeding waterbird communities are changing in response to climate warming, with a relative increase in warm-dwelling species, which are mainly thermal specialists. However, the interaction between natural habitat conversion (NHC) and temperature increases led to a net decrease in species richness and a relative increase in thermal generalists, regardless of their thermal niche position (either cold- or warm-dwelling). We did not observe an increase in CTI where the NHC was higher than $5 \%$ over 15 years.

\section{Community temperature changes in response to temperature increases}

We have shown that in the Mediterranean region, in response to a $0.5^{\circ} \mathrm{C}$ increase in winter temperature during the study period (1991-2010) (Mariotti et al. 2015), the CTI for non-breeding waterbirds increased in the absence of NHC. Observing an increasing CTI over time and with increasing regional temperature anomalies, we could expect that climate warming induced a thermal community adjustment according to the thermal affinities of the species (Devictor et al. 2008). Such a level of bird community adjustment to climate warming had already been observed (for review, see Pearce-Higgins and Green 2014), including in non-breeding waterbirds (Godet et al. 2011, Gaget et al. 2018).

Here, the changes in community thermal composition are more likely explained by the overall increase in temperature, using the year as a proxy, than by the regional (Mediterranean) or local 
(site) temperature anomaly increases. The composition and structure of waterbird communities at non-breeding sites seem more dependent on the conditions along the migratory flyway than on the local temperatures, as observed by Sauter et al. (2010). For these migratory birds, year is likely a proxy for the climatic conditions experienced across their overall distribution range and along their breeding, migration and non-breeding areas (Newton 2008). Conversely, the local winter temperature was a poor predictor of non-breeding waterbird community changes. This finding contrasts with those for breeding bird communities, which were greatly related to local climate variations (Gaüzère et al. 2015). A species range shift could also result in a time lag effect (Princé and Zuckerberg 2015), which occurs when the species shift depends on the temperature experienced during the previous years and not only on the current weather conditions (La Sorte and Jetz 2012). Therefore, the change in relative abundance has probably been smoothed over the years due to the birds' fidelity and longevity at their wintering sites, which may have reduced the response to local inter-annual variations (Maclean et al. 2008). Note that here we focused on the response to temperature increase, but species abundance, community composition and hence the CTI may also be affected by precipitation changes (Gaüzère et al. 2015) which could lead to a multi-directional species range shift (Tingley et al. 2009). Given that precipitations are predicted to decrease in the Mediterranean region (Mariotti et al. 2015), complementary studies should further investigate the impact of precipitation changes on non-breeding waterbird communities.

Species contributions to the $\mathrm{CTI}$ increase suggest that more species were experiencing a northern range expansion than a southern range reduction. The increase in CTI was mainly due to a relative increase in warm-dwelling species abundance ( $n=17,15 \%$ of the species), combined with decreases in the abundances of a few of cold-dwelling species ( $n=7,5 \%$ of the species) (Fig. 3, Appendix S2). The Mediterranean Basin represents the northern (Fig. 4A) and southern (Fig. 4B) distribution edges of those species contributing the most to a CTI increase. A population increase at the leading edge of a species distribution is one of the most common adjustments to climate warming observed in the northern hemisphere (Pearce-Higgins and Green 2014). This result indicates a likely positive effect of temperature increases on the population dynamics of warm-dwelling species (Gregory et al. 2009). Among these species, for example, the expansion of sedentary populations of the cold-sensitive cattle egret (Bubulcus ibis) was facilitated by milder winters in Europe (Hafner et al. 1992). Additionally, by decreasing their daily energy requirements (Wiersma and Piersma 1994), milder winters promote the northward shift of small shorebird species (Austin and Rehfish 2005). The relative decrease in cold-dwelling species abundance suggests a change at their trailing edge distribution (Thomas and Lennon 1999). As examples, the most abundant European breeding duck, the mallard (Anas platyrhynchos), is a cold-dwelling species with a positive contribution to the CTI increase, which shortened its migration distance at several flyway locations (Sauter et al. 2010, Gunnarsson et al. 2012). Similarly, the greylag goose (Anser anser) shifted its Mediterranean nonbreeding range to more northern European countries in the 1990s (Ramo et al. 2015) and at the same time had an overall growing breeding population across Europe (BirdLife 2017). Such changes in non-breeding distributions suggest a reduction in the migratory distances, which may increase bird fitness by allowing them to preserve their fat resources for reproduction and reducing mortality rates during migration (Gilroy 2017). Alternatively, a winter range shift could also diminish the potential risk of an increasing migration distance in the case of a breeding range shift (Zurell et al. 2018). In this study, however, we were unable to identify whether the trailing edge shift corresponded to a range contraction or to a displacement of the entire species distribution area in response to the temperature increase (Pearce-Higgins and Green 2014). Further work should be carried out at the species flyway scale to assess the actual expansion/contraction of the range and its consequences on population dynamics (e.g., Pavón-Jordán et al. 2015). 


\section{Interaction between climate warming and NHC}

Our results suggest that thermal community adjustment to temperature increase was disrupted towards an adjustment to both $\mathrm{NHC}$ and temperature increases, corresponding to an antagonistic interaction between the two drivers. The apparent antagonistic interaction led to a homogenization pattern of non-breeding waterbird communities over time, through a decrease in species richness, a relative decrease in thermal specialists and a relative increase in thermal generalist species. The result was independent of the CTI trend since there was no correlation between thermal niche position (STI) and thermal niche breadth (STR). Here, conversely to previous studies (e.g. Kerbiriou et al. 2009, Galewski and Devictor 2016), the observed decline in species richness over the homogenization process underpin the "losing species" pattern, occurring when species extirpation is higher than species colonization (Clavel et al. 2011). Interestingly, a higher number of specialist species increased when there is a temperature increase alone rather than when the NHC occurred (Fig. 3). This contrasts with other studies on breeding birds which found that the change in temperature induced a relative increase in generalist species (Davey et al. 2013, Gaüzère et al. 2015). In these studies however, the possible confounding interaction between temperature and land use changes was not considered. Antagonistic interactions are not frequently reported in the literature and therefore probably underestimate changes in biodiversity (Côté et al. 2016). Here the observed relative decrease in warm-dwelling specialists was found when the proportion of $\mathrm{NHC}$ was larger than $5 \%$ over 15 years (Fig. 2a), highlighting the importance of (i) investigating the interaction between land use change and climate warming (Sirami et al. 2016) and (ii) taking into account the magnitude of the changes even if they are relatively low (Oliver and Morecraft 2014).

Such finding provides crucial knowledge to improve future range projections (Pereira et al. 2010) and to prioritize conservation management on factors that can be locally managed, like the NHC (Brook et al. 2008).

\section{Conservation implications}

Our results highlight important conservation issues to mitigate the impact of climate change on migratory species. Some of the species that likely increase in abundance with a temperature increase are partial long-distance migrants, e.g., the black-winged stilt (Himantopus himantopus), glossy ibis (Plegadis falcinellus), and ruff (Calidris pugnax), which winter in sub-Saharan Africa, up to Maghreb and sporadically in southern Europe (Fig. 4A). However, in their African non-breeding grounds, these species are greatly impacted by habitat loss and degradation (Vickery et al. 2014), persecution, overexploitation and illegal killing (Bairlein 2016), and temperature and drought increases (Saether and Engen 2010). Thus, as climate warming is predicted to strengthen in the Mediterranean area (Mariotti et al. 2015), Mediterranean and European countries face increasing responsibilities to facilitate species adjustment to temperature increase by reducing the conversion of natural wetlands. Despite that the NHC was considered as a whole due to land cover classification used (Perennou et al. 2018), the diversity of land use threats on wetlands (Beltrame et al. 2015) encourages prioritisation of their impacts, notably by species specific investigations. In a global change context, these results have strong implications for biodiversity conservation and suggest that the adjustments of bird communities to climate warming can be improved by effective protected areas that will prevent NHC (Gaüzère et al. 2016, Lehikoinen et al. 2018, Peach et al. 2018).

A strong negative relationship between $\mathrm{NHC}$ and community adjustment to a temperature increase was detected, although the levels of $\mathrm{NHC}$ measured at the surveyed sites were lower than the rates reported for wetlands worldwide. The conversion for the 164 studied sites was on average $3 \%$ between 1990-2005 (ranging from 0 to 13\%), while wetlands, excluding man-made wetlands, declined by an average of 30\% between 1970 and 2008 globally (Davidson 2014, Dixon et al. 2016). This would suggest that the waterbird community adjustment to climate warming was greatly reduced at a global scale. 


\section{Acknowledgments:}

We acknowledge the ornithologists involved in the waterbird counts, the national coordinators from the 22 countries included in the study, and the International Waterbird Census (IWC) coordination units (Wetlands International, Tour du Valat, the National Office for Hunting and Wildlife (ONCFS), and the National IWC North African coordinators of GREPOM/BirdLife Morocco, the Direction Générale des Forêts (Algeria), AAO/BirdLife Tunisia, the Libyan Society for Birds and the Egyptian Environmental Affairs Agency) for providing help to national coordinators, centralizing and managing data and making this research possible.

We also thank N. Taylor, I. Geijzendorffer and M. Briga for their useful comments and improving the language of the manuscript.

This study was funded by the Foundation Tour du Valat, Foundation Prince Albert II de Monaco, Foundation Total, the French Ministry of "Transition écologique et solidaire" and the MNHN 227 doctoral school. We the three anonymous reviewer for useful comments on a previous version of this paper.

\section{References}

- Austin GE, Rehfisch MM. 2005. Shifting Nonbreeding Distributions of Migratory Fauna in Relation to Climatic Change. Global Change Biology 11(1):31-38.

- Bairlein F. 2016. Migratory Birds under Threat. Science 354(6312):547-548.

- Barnagaud JY, Devictor V, Jiguet F, Barbet-Massin M, Le Viol I, Archaux F. 2012. Relating Habitat and Climatic Niches in Birds. PLoS ONE 7(3):e32819.

- Beltrame C, Perennou C, Guelmami A. 2015. Évolution de I"occupation du sol dans les zones humides littorales du Bassin méditerranéen de 1975 à 2005. Méditerranée 125:97-111.

- BirdLife International. 2017. European birds of conservation concern: populations, trends and national responsibilities Cambridge, UK:BirdLife International.

- Breheny P, Burchett W. 2013. Visualization of regression models using visreg. R package, 115.

- Brook B, Sodhi N, Bradshaw C. 2008. Synergies among Extinction Drivers under Global Change. Trends in Ecology \& Evolution 23(8):453-460.

- Brown JH. 1984. On the Relationship between Abundance and Distribution of Species. The American Naturalist 124(2):255-79.

- Carboni M, Zelený D, Acosta ATR. 2016. Measuring Ecological Specialization along a Natural Stress Gradient Using a Set of Complementary Niche Breadth Indices. Journal of Vegetation Science 27(5):892-903.

- Clavel J, Julliard R, Devictor V. 2011. Worldwide Decline of Specialist Species: Toward a Global Functional Homogenization? Frontiers in Ecology and the Environment 9(4):222-28.

- Côté IM, Darling ES, Brown CJ. 2016. Interactions among Ecosystem Stressors and Their Importance in Conservation. Proceedings of the Royal Society B 283(1824):20152592.

- Davey CM, Devictor V, Jonzén N, Lindström Â, Smith HG. 2013. Impact of climate change on communities: revealing species' contribution. Journal of Animal Ecology 82(3):551-561.

- Davidson NC. 2014. How much wetland has the world lost? Long-term and recent trends in global wetland area. Marine Freshwater Research 65:934.

- Delany S. 2005. Guidelines for participants in the International Waterbird Census. Wetl. Int. Wagening, The Netherlands.

- Devictor V, Julliard R, Couvet D, Jiguet F. 2008. Birds are tracking climate warming, but not fast enough. Proceedings of the Royal Society B 275:2743-2748.

- Dixon MJR, Loh J, Davidson NC, Beltrame C, Freeman R, Walpole M. 2016. Tracking Global Change in Ecosystem Area: The Wetland Extent Trends Index. Biological Conservation 193:27-35.

- Eglington SM, Pearce-Higgins JW. 2012. Disentangling the Relative Importance of Changes in 
Climate and Land-Use Intensity in Driving Recent Bird Population Trends. PLOS ONE 7:e30407.

- Frishkoff LO, Karp DS, Flanders JR, Zook J, Hadly EA, Daily GC, M'Gonigle LK. 2016. Climate change and habitat conversion favour the same species. Ecology Letters 19(9):1081 1090.

- Gaget E, Galewski T, Jiguet F, Le Viol I. 2018. Waterbird Communities Adjust to Climate Warming According to Conservation Policy and Species Protection Status. Biological Conservation 227:205-212.

- Galewski T, Devictor V. 2016. When Common Birds Became Rare: Historical Records Shed Light on Long-Term Responses of Bird Communities to Global Change in the Largest Wetland of France. PLOS ONE 11:e0165542.

- Gaüzère P, Jiguet F, Devictor V. 2015. Rapid Adjustment of Bird Community Compositions to Local Climatic Variations and Its Functional Consequences. Global Change Biology 21(9):3367-78.

- Gaüzère $P$, Jiguet F, Devictor V. 2016. Can protected areas mitigate the impacts of climate change on bird's species and communities? Diversity and Distributions 4(15):2991-3003.

- Gilroy JJ. 2017. Stay-at-Home Strategy Brings Fitness Benefits to Migrants. Journal of Animal Ecology 86(5):983-86.

- Godet L, Jaffre M, Devictor V. 2011. Waders in winter: long-term changes of migratory bird assemblages facing climate change. Biology Letters 7:714-717.

- Gregory RD, et al. 2009. An Indicator of the Impact of Climatic Change on European Bird Populations. PLoS ONE 4(3):e4678.

- Grenouillet G, Comte L. 2014. Illuminating Geographical Patterns in Species' Range Shifts Global Change Biology 20(10):3080-91.

- Gunnarsson G, Waldenström J, Fransson T. 2012. Direct and Indirect Effects of Winter Harshness on the Survival of Mallards Anas Platyrhynchos in Northwest Europe. Ibis 154(2):307-317.

- Hafner H, Pineau O, Wallace JP. 1992. The effects of winter climate on the size of the Cattle Egret (Bubulcus ibis L.) population in the Camargue. Revue d'écologie-la Terre et la Vie 47.

- Hutchinson GE. 1957. A Treatise on. Limnology 1:243.

- Jiguet F, Julliard R, Thomas CD, Dehorter O, Newson SE, Couvet D. 2006. Thermal Range Predicts Bird Population Resilience to Extreme High Temperatures. Ecology Letters 9(12):1321-1330.

- Kerbiriou C, Le Viol I, Jiguet F, Devictor V. 2009. More species, fewer specialists: 100 years of changes in community composition in an island biogeographical study. Diversity and Distributions 15:641-648.

- La Sorte FA, Jetz W. 2012. Tracking of Climatic Niche Boundaries under Recent Climate Change: Niche Tracking under Recent Climate Change. Journal of Animal Ecology 81(4):91425.

- Lavorel S, et al. 2008. Assessing Functional Diversity in the Field - Methodology Matters! Functional Ecology 22(1):134-147.

- Lehikoinen P, Santangeli A, Jaatinen K, Rajasârkkâ A, Lehikoinen A. 2018. Protected Areas Act as a Buffer against Detrimental Effects of Climate Change-Evidence from Large-Scale, LongTerm Abundance Data. Global Change Biology 25(1):304-313.

- Maclean IMD, et al. 2008. Climate change causes rapid changes in the distribution and site abundance of birds in winter. Global Change Biology 14(11):2489-2500.

- Magnusson A, et al. 2017. Package „glmmTMB": Generalized linear mixed models using a template model builder. $R$ CRAN package version 0.1.3.

- Mariotti A, Pan Y, Zeng N, Alessandri A. 2015. Long-term climate change in the Mediterranean region in the midst of decadal variability. Climate Dynamics 44:1437-1456.

- Morice CP, Kennedy JJ, Rayner NA, Jones PD. 2012. Quantifying uncertainties in global and regional temperature change using an ensemble of observational estimates: The HadCRUT4 
data set. Journal of Geophysical Research:Atmospheres 117(D8).

- Nakagawa S, Schielzeth H. 2013. A General and Simple Method for Obtaining R 2 from Generalized Linear Mixed-Effects Models. Methods in Ecology and Evolution 4(2):133-142.

- Newbold T, et al. 2015. Global effects of land use on local terrestrial biodiversity. Nature 520:45-50.

- Newton I. 2008. The migration ecology of birds. Academic Press, London, UK.

- Oliver TH, Morecroft MD. 2014. Interactions between Climate Change and Land Use Change on? Biodiversity: Attribution Problems, Risks, and Opportunities. Wiley Interdisciplinary Reviews: Climate Change 5(3):317-35.

- Pavón-Jordán D, et al. 2015. Climate-Driven Changes in Winter Abundance of a Migratory Waterbird in Relation to EU Protected Areas. Diversity and Distributions 21(5):571-82.

- Peach MA, Cohen JB, Frair JL, Zuckerberg B, Sullivan P, Porter WF, Lang C. 2018. The value of protected areas to avian persistence across 20 years of climate and land- use change. Conservation Biology 33(2):423-433.

- Pearce-Higgins JW, Green RE. 2014. Birds and climate change: impacts and conservation responses. Cambridge University Press, pp. 171-198.

- Pereira HM, et al. 2010. Scenarios for Global Biodiversity in the 21st Century. Science 330:1496-1501.

- Perennou C, et al. 2018. Mapping Mediterranean wetlands with remote sensing: a goodlooking map is not always a good map. Advances in Ecological Research 58:243-277.

- Pinheiro J, Bates D, DebRoy S, Sarkar D. 2014. nlme: linear and nonlinear mixed effects models. $\mathrm{R}$ package version 3.1-117. http://CRAN.R-project.org/package=nlme.

- Poisot T, Bever JD, Nemri A, Thrall PH, Hochberg ME. 2011. A Conceptual Framework for the Evolution of Ecological Specialisation: Evolution of Ecological Specialisation. Ecology Letters 14(9):841-51.

- Princé K, Zuckerberg B. 2015. Climate Change in Our Backyards: The Reshuffling of North America"s Winter Bird Communities. Global Change Biology 21(2):572-85.

- R Development Core Team. 2015. R: A Language and Environment for Statistical Computing. R Foundation for Statistical Computing, Vienna.

- Ramo C, et al. 2015. Latitudinal-Related Variation in Wintering Population Trends of Greylag Geese (Anser Anser) along the Atlantic Flyway: A Response to Climate Change? PloS One 10(10):e0140181.

- Saether BE, Engen S. 2010. Population analyses. In Møller AP, Fiedler W, Berthold P. (Eds.). Effects of climate change on birds. Oxford University Press.

- Sauter A, Korner-Nievergelt F, Jenni L. 2010. Evidence of climate change effects on withinwinter movements of European Mallards Anas platyrhynchos. Ibis 152:600-609.

- Sirami C, Caplat P, Popy S, Clamens A, Arlettaz R, Jiguet F, Brotons L, Martin J-L. 2016. Impacts of global change on species distributions: obstacles and solutions to integrate climate

- and land use: Land-use and climate change integration. Global Ecology and Biogeography 26(4):385-394.

- Slatyer RA, Hirst M, Sexton JP. 2013. Niche Breadth Predicts Geographical Range Size: A General Ecological Pattern. Ecology Letters 16(8):1104-14.

- Thomas CD, Lennon JJ. 1999. Birds extend their ranges northwards. Nature 399(6733):213.

- Vickery JA, Ewing SR, Smith KW, Pain DJ, Bairlein F, Škorpilovâ J, Gregory RD. 2014. The Decline of Afro-Palaearctic Migrants and an Assessment of Potential Causes. Ibis 156(1):1-22.

- Wiersma P, Piersma T. 1994. Effects of Microhabitat, Flocking, Climate and Migratory Goal on Energy Expenditure in the Annual Cycle of Red Knots. The Condor 96(2):257-79.

- Zurell D, Graham CH, Gallien L, Thuiller W Zimmermann NE. 2018. Long-distance migratory birds threatened by multiple independent risks from global change. Nature climate change 8(11):992. 
- Zuur AF, Leno EN, Walker NJ, Saveliev AA, Smith GM. 2009. Mixed effects models and extensions in ecology with R. Statistics for biology and health. Springer, New York. 